\title{
Perceived social support among students of medical sciences
}

\author{
Freshteh Zamani-Alavijeh ${ }^{1}$, Fatemeh Raeesi Dehkordi², Parvin Shahry ${ }^{3}$
}

\author{
${ }^{1}$ Ph.D., Associate Professor, Department of Health Education and Promotion, School of Health, Isfahan University \\ of Medical Sciences, Isfahan \\ ${ }^{2}$ Ph.D. Candidate, Department of Health Education and Promotion, Student Research Center, School of Health, \\ Isfahan University of Medical Sciences, Isfahan, Iran \\ ${ }^{3}$ M.Sc., Lecturer, Faculty of Health, Social Determinants of Health Research Center, Ahvaz Jundishapur University \\ of Medical Sciences, Ahvaz, Iran
}

\section{Type of article: Original}

\begin{abstract}
Background: Social support is emotional and instrumental assistance from family, friends or neighbors, and has an important but different impact on individuals, mainly depending on contextual factors.

Objective: To determine the status of perceived social support and related personal and family characteristics of medical sciences students in Ahvaz, Iran.

Methods: In this cross-sectional study, the target population included the students of Ahvaz Jundishapur University of Medical Sciences in the second semester of 2013-2014, of whom 763 were selected by cluster random sampling method. The study tool was a two-part questionnaire containing 48 self-administered questions including 25 questions of measurements of personal and family characteristics and a Persian modified version of Vaux's social support scale (Cronbach's $\alpha=0.745$ ). Data were analyzed with T test, ANOVA and chi-square and using SPSS version 16 and 0.05 was considered as the level of significance.

Results: The mean score of the perceived social support was $17.06 \pm 3.6$ and $60.3 \%$ of them reported low social support. There was a significant relationship among the perceived social support and sex $(\mathrm{p}=0.02)$, faculty $(p<0.0001)$, ethnicity $(p=0.034)$ and the duration of weekly residence in dormitory $(p=0.031)$. But no significant relationship was found between this variable and other individual and familial characteristics.

Conclusion: Based on students' low social support and importance of social support in reducing stress and academic failure, the planners need to provide efficient supportive interventions for students.

Keywords: Social support, Medical student, Medical school
\end{abstract}

\section{Introduction}

The students are talented and popular members of the community, and future builders of the country whose further development is at risk due to their location change, sudden separation from family and the issues related to their education (1). Pressures and challenges along with the social cognitive changes of this course manifest the necessity of social planning for this group. In the meantime, knowledge, skills and the individuals' previous achievements are not the appropriate predictors of the individual's future performance, and emotion-oriented coping strategies are needed to deal with stress (2). The perceived social support is a social mechanism taken into consideration in recent years, and it refers to the importance of the social dimension of the individual (3). The perceived social support refers to people's belief about the level and quality of support available to them $(4,5)$. Indeed, social support reflects the individual's perceptions and impressions available and the interpersonal exchanges in a social network, and it is more important than the social support actually provided (6). "Perceived social support refers to an individual's

\section{Corresponding author:}

Parvin Shahry, Faculty of Health, Social Determinants of Health Research Center, Ahvaz Jundishapur University of Medical Sciences, Ahvaz, Iran.

Tel: +98.6133738269, Fax:+98.6133738282, Email: shahry_2001@yahoo.com and shahry-p@ajums.ac.ir

Received: November 26, 2016, Accepted: April 12, 2017, Published: June 2017

iThenticate screening: March 08, 2017, English editing: May 12, 2017, Quality control: May 26, 2017

(C) 2017 The Authors. This is an open access article under the terms of the Creative Commons Attribution-NonCommercialNoDerivs License, which permits use and distribution in any medium, provided the original work is properly cited, the use is non-commercial and no modifications or adaptations are made. 
belief that social support is available, is generally considered positive or negative, and provides what is considered as needed by that individual" (7). Hence, it is a complex and multi-faceted structure (8) and can be presented as emotional, instrumental, informational, or evaluation support. There are two views on the impact of social support on health. The direct model of social support has an immediate impact on health, and, in the indirect model, the social support functions like a bumper that supports the individuals against stressful events (9). In this regard, Orit and his colleagues believed that one may conclude whether one possesses social support or not, based on his or her past experiences, and if the answer is yes, the interaction with social network increases, and the negative effect of life events decreases (10).

According to self-determination theory, social support can function as a facilitator of desire efflorescence and internal potentials (11). Erik have pointed to the role of social communication in promoting a sense of security and physical and mental health (12). Other studies have pointed to the effective role of social support on positive attitude towards school assignments and sense of belonging to the school (13), development of emotional intelligence and sense of self-efficacy (14), reduction in stress of the environment (15), and flexibility (16). Generally, there is a negative correlation between the lack of perceived social support and academic failure (17), lower self-esteem (18), suicidal thoughts (19) and anxiety (20). As having social support is conditional on to health (21), high levels of social support lead a person to feel fewer psychological symptoms (22). Social support is affected by several factors such as communication competencies (23). Medical students are health professionals (24) who are struggling with the challenge and stress of transition from high school to the adult world stage (25) Previous studies have found high levels of stress among medical students $(26,27)$. They are perceived as being more likely to become ill than other students (28) and are in need of social support $(29,30)$. A school period is a section of life time in which many behavioral patterns will emerge or stabilize (31). Social relationships, expectations and new roles take shape in this period of time, which sometimes affects a person's performance and efficiency (32). Several studies found that the student's life and university setting was introduced as a stressful environment.. In non-native cases, unfamiliarity with the college environment or culture of the district, distance and separation from family, conflict with other people (33) and the desire for social contact versus study (34), could threaten their mental health. Therefore, reinforced factors that promote the health of students were considered to be critical (35). During student time the acceptable social support gain, sufficient perception, availability and satisfaction of receiving it, needs considerable attention (36). Social support is a predictor for compatibility with the campus (37), promoting confidence and work performance (38), self-efficacy and satisfaction (39), mental health in adulthood (40), stress reduction (41) and the ability to deal with interpersonal conflict (42). Studies have shown that when having support in pursuing their own goals; students felt happier and have had greater motivation to achieve goals and independence (43). Considering the positive and influential role of social support on academic success, and failure to do similar studies in the research environment, the perceived social support status and related personal and family characteristics of the students were studied, and it is expected that the current study could raise the general knowledge of the level of perceived social support status based on personal and family characteristics of the target group.

\section{Material and Methods}

\subsection{Research design and participants}

This cross-sectional study was carried out in the second semester of 2013-2014. The study populations were the students of Ahvaz Jundishapur University of Medical Sciences studying at the time of the research. The sample was 764 subjects who were selected to participate in the study according to the following value ( $\mathrm{s}=7, \mathrm{~d}=0.5$ and $\alpha=0.05$ ). Multistage sampling was used. At first, all (7) schools of the Ahvaz Jundishapur University of Medical Sciences were considered, as class and information of students ' population in every school was received via the Education Development Deputy, and then the sample was chosen by using cluster random sampling method. The number of each cluster was determined based on the faculty student population: Midwifery \& Nursing (135), Health (77), Rehabilitation (80), Pharmacy (65), Dentistry (86), Medicine (167), and Paramedics (121). Inclusion criteria was willingness to participate in the study and having not already participated in a similar study, and exclusion criteria was the freedom to leave the study.

\subsection{Measurement tool and data collection}

The data gathering tool was a questionnaire with 48 items in two parts. The first part included 25 questions for measurement of personal and family characteristics including sex, marital status, place of residence (dormitory and off-campus), course and field of study, parental education and job. The second part included 23 questions of the Vaux's social support questionnaire that contained three subscales to assess social support for family, friends (8 items each) and others (7 items). This tool was designed in 1986 (44), the theoretical structure scale which is based 
on Cobb's definition of social support measures the enjoyment of affection, assistance and attention of family members, friends and the others (45). The presented responses to each of the test items are placed on a yes/no scale. The questionnaire has a score between 23 and 46, each correct answer has a score, and higher scores indicate a higher level of perceived social support (46). In 1991, it was translated and validated into Persian and modified by Ebrahimi Ghavam (Cronbach's alpha $=0.9$ ) and the instrument has acceptable validity, and the internal consistency of which has been reported (47). In this survey, in order to study the face validity of instruments, thirty students who were similar to the samples in regard to the demographic variables were entered into the research, and were asked to comment about the directness and simplicity of the questionnaire. The questionnaire was modified based on students ' comments. Moreover, to determine the internal consistency of the questionnaire, fifty other students, who were not part of the study sample, completed it; Cronbach's alpha was 0.745 and was satisfactory. Data collection methods were in such a way that after obtaining permission from the educational assistant; the researcher attended the class before the start of the session. Then, explaining the survey and receiving completed students' consent forms, they were asked to complete the questionnaire at the same moment and deliver it to the researcher. In total, from the 775 provided questionnaires, 764 questionnaires were delivered by the students.

\subsection{Ethics of research}

After obtaining the relevant permits from the honorable Educational Assistant of the University and the related faculties, subjects were invited to participate in the study. For all subjects, professional ethics were observed, informed consent was obtained and each individual was assured of the confidentiality of the collected information.

\subsection{Statistical analysis}

After completing data collection, data were analyzed using SPSS version 16 (SPSS Inc., Chicago, Illinois, USA) and through statistics tests including ANOVA and Chi-square, 0.05 was considered statistically significant.

\section{Results}

This study was conducted on 764 students. Approximately 89 percent of the study sample were unemployed, and 86 percent were single. Table (1) shows the distribution of individual characteristics of the sample.

Table 1. Personal characteristics of Ahvaz Jundishapur University of Medical Sciences students.

\begin{tabular}{|c|c|c|c|}
\hline \multicolumn{2}{|l|}{ Variable } & Male (456) & Female (298) \\
\hline \multirow{2}{*}{\multicolumn{2}{|c|}{ Age $\mathrm{M} \pm \mathrm{SD}$ (year) }} & $21.43 \pm 2.74$ & $21.60 \pm 2.29$ \\
\hline & & $\mathrm{n}(\%)$ & $\mathrm{n}(\%)$ \\
\hline \multirow[t]{2}{*}{ Marital status } & Married & $59(12.6)$ & $40(13.4)$ \\
\hline & Single & $258(86.5)$ & $406(87.3)$ \\
\hline \multirow{7}{*}{ College } & Nursing and Midwifery & $100(21.5)$ & $35(11.7)$ \\
\hline & Health & $50(12.2)$ & $22(7.38)$ \\
\hline & Rehabilitation & $45(9.24)$ & $35(11.7)$ \\
\hline & Pharmacy & $31(6.66)$ & 34 (11.4) \\
\hline & Dental & $40(8.60)$ & $46(15.4)$ \\
\hline & Medical & $88(18.9)$ & $79(26.5)$ \\
\hline & Paramedical & $104(22.2)$ & $47(15.7)$ \\
\hline \multirow{2}{*}{ Occupation } & Employed & $33(11.07)$ & $46(9.8)$ \\
\hline & Unemployed & $265(88.9)$ & $419(90.01)$ \\
\hline \multirow{3}{*}{ City of birth } & Ahvaz city & $43(14.4)$ & $121(26.02)$ \\
\hline & Other cities in Khuzestan province & $88(29.5)$ & $187(40.2)$ \\
\hline & Other provinces & $167(56.04)$ & $157(33.7)$ \\
\hline \multirow[t]{4}{*}{ Family size } & $1-3$ & $57(12.2)$ & $62(20.8)$ \\
\hline & $4-6$ & $315(67.7)$ & $190(63.7)$ \\
\hline & $7-9$ & $87(18.7)$ & $40(4.13)$ \\
\hline & More than 9 & $6(1.29)$ & $6(2.01)$ \\
\hline \multirow[t]{5}{*}{ Ethnicity } & Persian & $140(30.1)$ & $82(27.5)$ \\
\hline & Lur & $161(34.6)$ & $112(37.5)$ \\
\hline & Kurd & $42(9.03)$ & $30(10.06)$ \\
\hline & Arab & $61(13.1)$ & $30(10.06)$ \\
\hline & Other & $61(13.1)$ & $44(14.7)$ \\
\hline
\end{tabular}


http://www.ephysician.ir

According to the statement of responses the majority of fathers of students were employed and $78.5 \%$ of their mothers were housewives. The majority of parents' educational level was high school with fathers (26.9), and mothers (28.9). The social supports mean score was $36.95 \pm 3.23$ which is in range of 25-42. The result of the Chisquare test showed that the mean score of the perceived social support in male students was higher than the females $(\mathrm{p}=0.02)$. The students residing in the dormitories during the work days (Saturday to Wednesday) stated a higher level of social support $(\mathrm{p}=0.031)$. Also, Chi-square test results showed that there was a significant relationship between perceived social support and ethnicity $(p=0.034)$, and faculty $(p<0.001)$. Except for the fathers' job $(p=0.03)$, there were no significant relationships among other personal and family characteristics of students such as marital status, occupation, residence in the dormitory at the weekend, city of family residency and mean score of the perceived social support. Table (2) and (3) show the relationship between the mean score of the perceived social support and personal and family characteristics of the subjects.

Table 2. The relationship between the mean score of perceived social support and personal characteristics of Ahvaz Jundishapur University of Medical Sciences students.

\begin{tabular}{|c|c|c|c|c|}
\hline \multicolumn{2}{|l|}{ Variables } & $\mathrm{n}(\%)$ & Mean \pm SD & $\mathrm{p}$-value \\
\hline \multirow[t]{2}{*}{ Sex } & \multirow{2}{*}{$\begin{array}{l}\text { Male } \\
\text { Female }\end{array}$} & $298(39.1)$ & $36.67733 \pm 3.990$ & \multirow[t]{2}{*}{0.02} \\
\hline & & $465(60.9)$ & $37.3450 \pm 3.9573$ & \\
\hline \multirow[t]{2}{*}{ Marital status } & Married & $99(13)$ & $36.9707 \pm 3.2687$ & \multirow[t]{2}{*}{0.357} \\
\hline & Single & $664(87)$ & $36.8069 \pm 2.9759$ & \\
\hline \multirow[t]{7}{*}{ College } & Nursing and Midwifery & $135(17.74)$ & $37.6355 \pm 2.9545$ & \multirow[t]{7}{*}{$<0.0001$} \\
\hline & Health & $77(10.11)$ & $37.0599 \pm 2.62950$ & \\
\hline & Rehabilitation & $80(19.51)$ & $36.5059 \pm 3.06292$ & \\
\hline & Pharmacy & $65(8.55)$ & $37.2496 \pm 2.91360$ & \\
\hline & Dental & $86(11.3)$ & $37.2603 \pm 2.91157$ & \\
\hline & Medical & $167(21.94)$ & $35.9012 \pm 3.69825$ & \\
\hline & Paramedical & $151(19.84)$ & $37.3704 \pm 3.48795$ & \\
\hline \multirow[t]{2}{*}{ Occupation } & Employed & $79(10.35)$ & $37.5686 \pm 2.78933$ & \multirow[t]{2}{*}{0.09} \\
\hline & Unemployed & $684(89.65)$ & $36.8906 \pm 3.28519$ & \\
\hline \multirow[t]{5}{*}{ Ethnicity } & Persian & $222(29)$ & $37.4251 \pm 3.1599$ & \multirow[t]{5}{*}{0.034} \\
\hline & Lur & $273(35.77)$ & $36.764 \pm 3.1922$ & \\
\hline & Kurd & $72(5.50)$ & $36.6681 \pm 3.7658$ & \\
\hline & Arab & $91(11.92)$ & $36.9771 \pm 3.3947$ & \\
\hline & Other & $105(13.76)$ & $36.6389 \pm 2.9199$ & \\
\hline \multirow[t]{3}{*}{ Stay in dormitory on working days } & Ever & $380(49.8)$ & $37.2340 \pm 3.1984$ & \multirow[t]{3}{*}{0.031} \\
\hline & Sometimes & $151(19.8)$ & $36.6481 \pm 3.2827$ & \\
\hline & Never & $232(30.4)$ & $36.6996 \pm 3.2449$ & \\
\hline \multirow[t]{3}{*}{ Stay in dormitory on the weekend } & Ever & $200(2.62)$ & $37.0839 \pm 3.4673$ & \multirow[t]{3}{*}{0.279} \\
\hline & Sometimes & $274(35.9)$ & $37.1473 \pm 3.1051$ & \\
\hline & Never & $289(37.87)$ & $36.6850 \pm 3.1872$ & \\
\hline \multirow[t]{4}{*}{ Family size } & $1-3$ & $19(15.6)$ & $36.560 \pm 3.1720$ & \multirow[t]{4}{*}{0.37} \\
\hline & $4-6$ & $505(66.2)$ & $36.6184 \pm 4.2323$ & \\
\hline & $9-7$ & $127(16.65)$ & $36.9771 \pm 3.4561$ & \\
\hline & More than 9 & $12(1.57)$ & $36.5430 \pm 4.3212$ & \\
\hline \multirow[t]{3}{*}{ Residence of Student } & Dormitory & $487(63.82)$ & $37.1772 \pm 3.1676$ & \multirow[t]{3}{*}{$<0.0001$} \\
\hline & Student house & $71(9.3)$ & $35.2884 \pm 3.8782$ & \\
\hline & House & $205(26.87)$ & $37.0064 \pm 2.9980$ & \\
\hline
\end{tabular}


Table 3. The relationship among the mean score of perceived social support and family characteristics of Ahvaz Jundishapur University of Medical Sciences students.

\begin{tabular}{|c|c|c|c|c|}
\hline \multicolumn{2}{|l|}{ Variables } & $\mathrm{n}(\%)$ & Mean \pm SD & $\mathrm{p}$-value \\
\hline \multirow[t]{5}{*}{ Father's occupation } & Worker & $34(4.46)$ & $37.0294 \pm 3.457$ & \multirow{5}{*}{0.03} \\
\hline & Employee & $311(40.86)$ & $37.0358 \pm 3.2959$ & \\
\hline & Self employed & $243(31.93)$ & $37.1609 \pm 3.0668$ & \\
\hline & Jobless & $21(2.76)$ & $37.3934 \pm 2.5960$ & \\
\hline & Other & $152(19.97)$ & $36.3455 \pm 3.3725$ & \\
\hline \multirow[t]{2}{*}{ Mother's occupation } & Housewife & $599(78.5)$ & $36.9246 \pm 3.2850$ & \multirow[t]{2}{*}{0.072} \\
\hline & Employee & $152(19.9)$ & $37.0658 \pm 3.1470$ & \\
\hline \multirow[t]{5}{*}{ Paternal educational level } & Illiterate & $58(7.6)$ & $36.2796 \pm 3.3752$ & \multirow[t]{5}{*}{0.20} \\
\hline & Primary & $127(16.6)$ & $37.0092 \pm 3.4768$ & \\
\hline & Secondary & $85(11.1)$ & $37.1519 \pm 2.6855$ & \\
\hline & Diploma & $200(26.2)$ & $37.2915 \pm 2.9477$ & \\
\hline & College & $289(37.9)$ & $36.7621 \pm 3.4375$ & \\
\hline \multirow[t]{5}{*}{ Maternal educational level } & Illiterate & $98(12.87)$ & $36.3416 \pm 3.935$ & \multirow[t]{5}{*}{0.065} \\
\hline & Primary & $156(20.5)$ & $37.0948 \pm 3.7631$ & \\
\hline & Secondary & $119(15.63)$ & $36.8294 \pm 3.0556$ & \\
\hline & Diploma & $221(29)$ & $37.4588 \pm 2.8735$ & \\
\hline & College & $167(21.94)$ & $37.6202 \pm 3.3149$ & \\
\hline
\end{tabular}

\section{Discussion}

The purpose of this study was to show the correlation of the perceived social support among the university students and personal and family characteristics. The results showed that most of the students received low levels of the perceived social support and emphasized the need to design appropriate interventions, whereas Chi, Cho (48), Akouchekian (49) Zimet (50) and Mansorian (51) reported average and quite high levels of perceived social support by the students. These different findings of studies may be resulted from applying various tools. In fact, social support, by providing financial, informational and emotional support helps to deal with stress (52). Current study showed that there were no significant relationships between age and social support, perhaps, this is due to the target group being almost matched in terms of age but in Shahahmadi (53) and Mansorian (51) studies, younger students had lower social support scores. There was significant correlation between the perceived social support and gender so that males had higher perceived social support, and a Soltani study confirms these findings (54). Males and females have different needs; male students have already experienced separation from the family and have been provided with their needs through friends and peers, and cited higher levels of social support. This study disproves the findings of Masoudi based on the lack of relation between two factors (55), Landman (56), Cochrane (57) and Peyravi (58) that females have higher levels of social support. Differences between results, related to time and cultural contexts. On the other hand, students living in dormitories reported higher levels of social support despite the possible stress, different challenges that may result from exposure to new cultures, passing over the teenage stage, and separation from their parents. Results from this study confirmed results of Soul (24), and Masoudi et al (56) based on dormitory students showing better academic performance, but Abazari (59) and Peyravi et al (58), indicated that social support from the family is more important than from friends. It could be said that dormitory dwelling is a small portrait of modern society and as a result of the residence's shared interests and scientific environment, is a source of support. Factors such as horizontal communication between students and participation in clubs or associations could help their mental health (60). Previous studies have shown that first year students may experience higher stress than second year students because they have lower social support in their transition to university (61). The dormitory environment affects the quality of a student's life (62), so, this environment must respond to the needs of all age groups (63) and promote their interpersonal skills to provide a sense of empathy between them (64). Bankston believed that students will consider their friends' views and attitudes to be more important than that of their parents, and they tended to receive their accepted support more from their friends for some interests such as music, entertainment and dress codes (65). It may be true in the case of subjects of the present study, so that the students staying in student housing expressed lower levels of social support due to their restrictions' on receiving family support, and medical school students stated lower levels of social support. Medicine college students expressed lower social support and this does not confirm Missourian's study findings (51). So that other research has pointed to a lack of effective communication among the target groups in the health system (66). It seems that universities are obliged to train graduates with sufficient capacity for promoting public health, but they 
may have failed to meet the needs and skills of communication (67) and it is required that appropriate intervention, especially for medical students, commonly encountered with clinical stressful conditions in the workplace are implemented.

The finding showed that the children of mothers with higher levels of education reported the higher level of social support, which did not apply in cases of uneducated fathers. There are different theories in the context of explaining these findings. Studies showed that education can affect one's perceptions of others and providing social support (68). Parker declares that as parents and adults have agreement with teens, still their influence is limited, parents only affect them on moralities, social values and understanding the world (69). In this study, there were significant relationships between social support and the fathers' occupation, which seems that considering a few students were employed; the father's job through a mediator named revenue affected the social support, which needs more study. Additionally, among people who do not have a good job or appropriate skills, literature reported that social support score is lower than others (70). Furthermore, between full-time employees, due to them being unable to take up other activities, they have experienced lower social support and higher stress (71). Although, Elena (72) and Boen (73) reported association between the income with social support and stress, Nazari `s findings indicate no relation between the two variables (74). In a research on patients suffering from cancer and hemodialysis, it has been mentioned that the perceived social support in people who are in a more favorable economic situation is better than those with poor or average economic state (75). Yan also concurs with this relationship. It is likely that the economic recovery was associated with an increase in social relations that eventually causes social support and increases its perception (76). Social support is different in the context of cultural, social and economic diversity (77). Iran is a multi-ethnic society of which, half of the population are Fars and almost one-third are Turks and Kurds, and onesixth are of other ethnic groups (78). The ethnic diversity was observed in the current study. According to the findings, Fars stated the higher scores of social support. The population of other ethnic groups is lower; the communication range is limited, and probably reported the lower level of social support. The ethnic diversity in social support is mainly due to the differences in economic and social characteristics such as education and training. In several studies, the effect of ethnicity on attitudes, personal, social and physical preferences of students (79), type of received social support (80), and in American culture, differences between Hispanics and people of African origin in the use and quality of social support for coping with stress (81) are argued. The current study has limitations that can be noted in forms of cross-sectional study which, in order to gain more detailed information, is better to take students to be surveyed for a longer period of time (from the entry time to university until graduation).

\section{Conclusions}

This study showed that the mean score of social support for students is low. Among the samples, female medical students are at higher risk and should be given appropriate attention for interventional programs. Success in the university requires adapting to events related to the new environment. The students must gain the required support to succeed. Therefore, it is necessary that academic advisers with appropriate assessment teach coping skills to students to ask for more supportive care. It is predicted that by providing social support and reducing the sources of stress in the academic environment, depression and stress greatly decreases. Psychological factors such as the emotional relationship between the child and parents and parenting methods can affect the perceived social support and must be considered in subsequent research, also, the perceived social supports were studied qualitatively to reveal its hidden aspects. Despite the fact that ethno-cultural factors have a decisive role in shaping attitudes and behaviors of the population, few studies and researches have surveyed them and they are needed to be mentioned more comprehensively in the subsequent studies. According to the effect of the social support on the student's progress, it is better to mention valid indicators in this context.

\section{Acknowledgments:}

This research was funded by Ahvaz Jundishapur University of Medical Sciences (Proposal number: SDH-9209). Special thanks go to the Deputy of Research and Technology. The authors gratefully acknowledge those students who participated in this study.

\section{Conflict of Interest:}

There is no conflict of interest to be declared.

\section{Authors' contributions:}

All authors contributed to this project and article equally. All authors read and approved the final manuscript. 


\section{References:}

1) Zeyghami R, Sharifi F, Ayatollahi A, Ashkani H. A survey of stress factors in nursing students in Shiraz University of Medical Sciences. Tehran Medical student's mental health national congress. (2004): 16.

2) Ghodusi M, Heidari M, Sharifi Neyestanak N, Shahbazi S. Correlation of perceived social support and some of the demographic factors in patients with Multiple Sclerosis. Journal of Health Promotion Management. 2013; 2(1): 24-31.

3) Matsuda T, Tsuda A, Kim E, Deng K. Association between Perceived Social Support and Subjective WellBeing among Japanese, Chinese, and Korean College Students. Psychology. 2014; 5(6): 491-9. doi: 10.4236/psych.2014.56059.

4) Burton HJ, Kline SA, Lindsay RM, Heidenheim P. The role of support in influencing outcome of end-stage renal disease. Gen Hosp Psychiatry. 1988; 10(4): 260-6. doi: 10.1016/0163-8343(88)90033-3. PMID: 3417126.

5) Shahry P, Kalhori SR, Esfandiyari A, Zamani-Alavijeh F. A Comparative Study of Perceived Social Support and Self-Efficacy among Women with Wanted and Unwanted Pregnancy. Int J Community Based Nurs Midwifery. 2016; 4(2): 176-85. PMID: 27218115, PMCID: PMC4876786.

6) Cohen LM, McChargue DE, Collins FL. The Health Psychology Handbook: Practical Issues for the Behavioral Medicine Specialist. Thousand Oaks, California: Sage Publications; 2003.

7) Mattson M, Gibb Hall J. Health as Communication Nexus: A Service Learning Approach. Iowa, United States: Kendall Hunt Publishing Co; 2011; 184.

8) Dakhte Haroni M. Correlation between social support and health in of selected zones of Tehran. (Master thesis), Tehran: School of Nursing \& Midwifery Shahid Beheshti University of Medical Sciences, 2009.

9) Abdollahzade Rafi M, Hassanzadeh M, Ahmadi S, taheri M, Hosseini MA. Relationship between social support with depression and anxiety during third trimester pregnancy. Iranian Journal of Nursing Research. 2012; 7(26): 1-10.

10) Oritt EJ, Paul SC, Behrman JA. The perceived support network inventory. Am J Community Psychol. 1985; 13(5): 565-82. doi: 10.1007/BF00923268. PMID: 4072977.

11) Schwarzer R, Knoll N. Functional roles of social support within the stress and coping process: A theoretical and empirical overview. International journal of psychology. 2007; 42(4): 243-52. doi: 10.1080/00207590701396641.

12) Lönnqvist JE, Deters FG. Facebook friends, subjective well-being, social support, and personality. Computers in Human Behavior. 2016; 55: 113-20. doi: 10.1016/j.chb.2015.09.002.

13) Danielsen AG, Wiium N, Wilhelmsen BU, Wold B. Perceived support provided by teachers and classmates and students' self-reported academic initiative. J Sch Psychol. 2010; 48(3): 247-67. doi: 10.1016/j.jsp.2010.02.002. PMID: 20380949.

14) Adelabu DH. Time perspective and school membership as correlates to academic achievement among African American adolescents. Adolescence. 2007; 42(167): 525-38. PMID: 18047236.

15) Rostami R, Shahmohamadi K, Ghaedi G, Besharat MA, Akbari Zardkhaneh S, Nosratabadi M. Relations among self-efficacy, emotional intelligence and perceived social support in university students. The Horizon of Medical Sciences. 2010; 16(3): 46-54.

16) Rathus SA. Psychology: concepts and connections. 8rd ed. London: Thomason, 10th ed. 169-83.

17) Mäkikangas A, Kinnunen U. Psychosocial work stressors and well-being: Self-esteem and optimism as moderators in a one-year longitudinal sample. Personality and individual differences. 2003; 35(3): 537-57. doi: 10.1016/S0191-8869 (02)00217-9.

18) Domagała-Zyśk E. The significance of adolescents' relationships with significant others and school failure. School Psychology International. 2006; 27(2): 232-47. doi: 10.1177/0143034306064550.

19) Mo'tamedi H, Nikian Y, Reza-Zadeh SD. Study of prevalence of depression in Afghanian refugees in Bardsir's camp. Journal of Rehabilitation. 2003; 4(1): 22-7.

20) Karademas EC. Self-efficacy, social support and well-being: The mediating role of optimism. Personality and individual differences. 2006; 40(6): 1281-90. doi: 10.1016/j.paid.2005.10.019.

21) Reblin M, Uchino Bert N. Social and Emotional Support and its Implication for Health. Curr Opin Psychiatry. 2008; 21(2): 201-5. doi: 10.1097/YCO.0b013e3282f3ad89.

22) Stroobe W, Zech E, Stroebe MS, Abakoumkin G. Does social support help in bereavement? Journal of social and Clinical Psychology. 2005; 24(7): 1030-50. doi: 10.1521/jscp.2005.24.7.1030.

23) Romero DH, Riggs SA, Ruggero C. Coping, family social support, and psychological symptoms among student veterans. Journal of Counseling Psychology. 2015; 62(2): 242. doi: 10.1037/cou0000061. 
24) Kim HW, Kim MR. An Analysis of Factors That Affect Social Support of Students in a Nursing University. Advanced Science and Technology Letters. 2015; 115: 1-6. doi: 10.14257/astl.2015.115.01.

25) Lubker JR, Etzel EF. College adjustment experiences of first-year students: Disengaged athletes, nonathletes, and current varsity athletes. Journal of Student Affairs Research and Practice. 2007; 44(3): 457-80. doi: 10.2202/1949-6605.1831.

26) Tyssen R, Hem E, Vaglum P, Grønvold NT, Ekeberg Ø. The process of suicidal planning among medical doctors: predictors in a longitudinal Norwegian sample. J Affect Disord. 2004; 80(2-3): 191-8. doi: 10.1016/S0165-0327(03)00091-0. PMID: 15207932.

27) Dahlin M, Joneborg N, Runeson B. Stress and depression among medical students: A cross - sectional study. Med Educ. 2005; 39(6): 594-604. doi: 10.1111/j.1365-2929.2005.02176.x. PMID: 15910436.

28) Morgen CS, Bové KB, Larsen KS, Kjaer SK, Grønbaek M. Association between smoking and the risk of heavy drinking among young women: a prospective study. Alcohol Alcohol. 2008; 43(3): 371-5. doi: 10.1093/alcalc/agn001. PMID: 18223292.

29) Kwon KN, Choi EH. Factors affecting career identity of nursing students. Journal of Korean Public Health Nursing. 2010; 24(1): 19-28.

30) Lee KS. The relation between social support, career decision-making self-efficacy and career identity of university students. Unpublished master's thesis, Sookmyung Womans University, Seoul. 2009.

31) Shojaa M, Jouybari L, Qorbani M, Sanagoo A, Shojaee H, Kajoori ZK, et al. Prevalence and cause of smoking among the dormitories students in Gorgan University of Medical Sciences. Pejouhandeh. 2010; 15(3): 123-8.

32) Lotfi MH, Aminiyan AH, Nori Shadkam M, Gomizadeh A, Zare M. Evaluation of mental health of Shahid Sadoghi medical sciences university students. Teb \& Tazkiye. 2007; 6(66-67): 49-56.

33) Karami S, Piraste A. Evaluation of mental health of Zanjan Medical Sciences University students. Journal of Zanjan University of Medical Sciences. 2001; (35): 66-73.

34) Hosseini HS, Sadeghi A, Rajabzadeh R, Rezazadeh J, Nabavi SH, Ranaei M, et al. Mental health and related factor in students of north khorasan university of medical sciences. Journal of North Khorasan University of Medical Sciences. 2011; 3(2): 23-8.

35) Baldwin DR, Chambliss LN, Towler K. Optimism and stress: An African-American college student perspective. College Student Journal. 2003; 37(2): 276-86.

36) Tian L, Liu B, Huang S, Huebner ES. Perceived social support and school well-being among Chinese early and middle adolescents: The mediational role of self-esteem. Social indicators research. 2013; 113(3): 991 1008. doi: 10.1007/s11205-012-0123-8.

37) Siedlecki KL, Salthouse TA, Oishi S, Jeswani S. The relationship between social support and subjective well-being across age. Soc Indic Res. 2014; 117(2): 561-76. doi: 10.1007/s11205-013-0361-4. PMID: 25045200, PMCID: PMC4102493.

38) Zimmer Z, Chen FF. Social support and change in depression among older adults in Taiwan. Journal of Applied Gerontology. 2012; 31(6): 764-82. doi: 10.1177/0733464811401353.

39) Wong DF, Chang Y, He X, Wu Q. The protective functions of relationships, social support and self-esteem in the life satisfaction of children of migrant workers in Shanghai, China. Int J Soc Psychiatry. 2010; 56(2): 143-57. doi: 10.1177/0020764009102755. PMID: 20207677.

40) Ratelle CF, Simard K, Guay F. University students' subjective well-being: The role of autonomy support from parents, friends, and the romantic partner. Journal of Happiness Studies. 2013; 14(3): 893-910. doi: 10.1007/s10902-012-9360-4.

41) DeLongis A, Holtzman S. Coping in context: The role of stress, social support, and personality in coping. J Pers. 2005; 73(6): 1633-56. doi: 10.1111/j.1467-6494.2005.00361.x. PMID: 16274448.

42) Turner BJ, Cobb RJ, Gratz KL, Chapman AL. The role of interpersonal conflict and perceived social support in non-suicidal self-injury in daily life. J Abnorm Psychol. 2016; 125(4): 588-98. doi: 10.1037/abn0000141. PMID: 26845256.

43) Akbari E. Compare the efficacy of transactional analysis therapy with the cognitive-behavioral therapy in improving symptoms of love failure students. University of Tabriz. 2011: 174.

44) Karimi Y, Bashirpur M, Khabbaz M, Hedayati AA. Comparison between perfectionism and social support dimensions and academic burnout in students. Procedia-Social and Behavioral Sciences, 5th World Conference on Psychology, Counseling and Guidance. 2014; 159: 57-63. doi: 10.1016/j.sbspro.2014.12.328.

45) Cobb S. Presidential Address-1976. Social support as a moderator of life stress. Psychosom Med. 1976; 38(5): 300-14. PMID: 981490. 
46) Bahrainian A, Yari M. The Relationship between Locus of Control and Social Support with Social Adjustment in Vocational School's Trainees in Tehran. J Appl Environ Biol Sci. 2014; 4(4): 271-7.

47) Ebrahimi S. Check the validity of the three concepts of locus of control, self-esteem and support social, educational psychology master's thesis, Faculty of Psychology and Educational, Islamic Azad University. 1992.

48) Chi I, Chou KL. Social support and depression among elderly Chinese people in Hong Kong. Int J Aging Hum Dev. 2001; 52(3): 231-52. doi: 10.2190/V5K8-CNMG-G2UP-37QV. PMID: 11407488.

49) Akouchekian SH, Roohafza HR, Hasan zadeh A, Mohammad Sharifi H. Relation between social support and coping with stress in nurses in psychiatric ward. Journal of Guilan University of Medical Sciences. 2009; 18(69): 41-6.

50) Zimet GD, Dahlem NW, Zimet SG, Farley GK. The multidimensional scale of perceived social support. Journal of personality assessment. 1988; 52(1): 30-41. doi: 10.1207/s15327752jpa5201_2.

51) Mansourian M, Solhi M, Adab Z, Latifi M. Relationship between dependence to mobile phone with loneliness and social support in University students. Razi Journal of Medical Sciences. 2014; 21(120): 1-8.

52) DiMatteo MR. Martin LR. Health Psychology. New York: Pearson Education; 2013.

53) Shaahmadi F, Shojaeizadeh D, Sadeghi R. Social support and its effective factors in the Afghan immigrants in Savojbolagh County. J Health System Research. 2014; 10(1): 106-13.

54) Reza Soltani P, Ghanbari Khanghah A, Moridi M. Comparison of health related quality of life in dormitory and non-dormitory students. Holistic Nursing and Midwifery Journal. 2015; 24(4): 38-45.

55) Masoudi A, Mohammadi M. Examinning the effects of residence and gender on college student perceptions and academic performance E. the journal Social Science and Humanities of Shiraz University. 2007; 25: 4(49): $185-200$.

56) Landman-Peeters KM, Hartman CA, van der Pompe G, den Boer JA, Minderaa RB, Ormel J. Gender differences in the relation between social support, problems in parent-offspring communication, and depression and anxiety. Soc Sci Med. 2005; 60(11): 2549-59. doi: 10.1016/j.socscimed.2004.10.024. PMID: 15814180.

57) Cochrane R. The social creation of mental illness. Addison-Wesley Longman Ltd; 2014.

58) Peyravi H, Hajebi A, Panaghi L. A survey on the relation between social support and mental health in students of Tehran University. Health System Research. 2010; 6(2): 301-7.

59) Lakzaei H, Abazar F, Mansouri A, Saboori A. The Survey of relationship between social supports with mental health of students in Kerman medical university. Teb va tazkiyeh. 2016; 24(2): 9-18.

60) Karami Pour A, Neamati MA. Analyzing challenges and strategies for turning dormitory University of Allameh Tabatabai small learning communities. Research leadership and Management Training Quarterly. 2015; 1(1).

61) Reeve KL, Shumaker CJ, Yearwood EL, Crowell NA, Riley JB. Perceived stress and social support in undergraduate nursing students' educational experiences. Nurse Educ Today. 2013; 33(4): 419-24. doi: 10.1016/j.nedt.2012.11.009. PMID: 23246284.

62) Xie ZG, Hui JQ. Research on the Problems in Dormitory Culture in Higher Vocational Colleges Based on Quantitative Study. In Advanced Materials Research. 2014; (926-930): 4598-601. Trans Tech Publications. doi: 10.4028/www.scientific.net/AMR.926-930.4598.

63) Kılıçaslan H. Design of Living Spaces in Dormitories. Procedia-Social and Behavioral Sciences. 2013; 92 : 445-51. doi: 10.1016/j.sbspro.2013.08.699.

64) Lin CY, Wu SW, Wu SF, Pan BS, Liao HC. Effects of Service-learning in a University in Taiwan. Procedia-Social and Behavioral Sciences. 2014; 116: 902-6. doi: 10.1016/j.sbspro.2014.01.317.

65) Bankston III CL, Caldas SJ. Family structure, schoolmates, and racial inequalities in school achievement. Journal of Marriage and the Family. 1998; 60(3): 715-23. doi: 10.2307/353540.

66) Mohammadi F, Hussein MA. Rehabilitation Sciences Students' Perception from Clinical Self-Efficacy Compared to Evaluation by Clinical Teachers. Iranian Journal of Medical Education. 2010; 10(2): 155-63.

67) Shariati M, Yunesian M, Vash JH. Mental health of medical students: a cross-sectional study in Tehran. Psychol Rep. 2007; 100(2): 346-54. doi: 10.2466/pr0.100.2.346-354. PMID: 17564208.

68) Devereux PG, Weigel DJ, Ballard-Reisch D, Leigh G, Cahoon KL. Immediate and longer-term connections between support and stress in pregnant/parenting and non-pregnant/non-parenting adolescents. Child and Adolescent Social Work Journal. 2009; 26(5): 431-46. doi: 10.1007/s10560-009-0175-z.

69) Parker JG, Asher SR. Peer relations and later personal adjustment: Are low-accepted children at risk? Psychol Bull. 1987; 102(3): 357-89. doi: 10.1037/0033-2909.102.3.357. PMID: 3317467. 
70) Dalgard OS, Mykletun A, Rognerud M, Johansen R, Zahl PH. Education, sense of mastery and mental health: results from a nationwide health monitoring study in Norway. BMC Psychiatry. 2007; 7: 20. doi: 10.1186/1471-244X-7-20. PMID: 17519014, PMCID: PMC1887526.

71) Dziak E, Janzen BL, Muhajarine N. Inequalities in the psychological well-being of employed, single and partnered mothers: the role of psychosocial work quality and work-family conflict. Int J Equity Health. 2010; 9: 6. doi: 10.1186/1475-9276-9-6. PMID: 20175914, PMCID: PMC2837665.

72) Rousou E, Kouta C, Middleton N. Association of social support and socio-demographic characteristics with poor self-rated health and depressive symptomatology among single mothers in Cyprus: a descriptive crosssectional study. BMC Nurs. 2016; 15: 15. doi: 10.1186/s12912-016-0134-x. PMID: 26937221, PMCID: PMC4774165.

73) Bøen H, Dalgard OS, Bjertness E. The importance of social support in the associations between psychological distress and somatic health problems and socio-economic factors among older adults living at home: a cross sectional study. BMC Geriatr. 2012; 12: 27. doi: 10.1186/1471-2318-12-27. PMID: 22682023, PMCID: PMC3464708.

74) Nazari M, Ghasemi S, Vafaei H, Fararouei M. The perceived social support and its relationship with some of the demographic characteristics in Primigravida pregnant women. International Journal of Nursing and Midwifery. 2015; 7(9): 141-5. doi: 10.5897/IJNM2015.0186.

75) Rambod M, Rafii F. Perceived social support and quality of life in Iranian hemodialysis patients. J Nurs Scholarsh. 2010; 42(3): 242-9. doi: 10.1111/j.1547-5069.2010.01353x. PMID: 20738734.

76) Yan H, Sellick K. Quality of life of Chinese patients newly diagnosed with gastrointestinal cancer: a longitudinal study. Int J Nurs Stud. 2004; 41(3): 309-19. doi: 10.1016/j.ijnurstu.2003.10.004. PMID: 14967188 .

77) Burstrom B, Whitehead M, Clayton S, Fritzell S, Vannoni F, Costa G. Health inequalities between lone and couple mothers and policy under different welfare regimes-the example of Italy, Sweden and Britain. Soc Sci Med. 2010; 70(6): 912-20. doi: 10.1016/j.socscimed.2009.11.014. PMID: 20060633.

78) Abbasi-Shavazi MJ, Jones GW. Socio-economic and demographic setting of Muslim populations. Islam, the State and Population. 2001.

79) Shakeri ski SH, Lytkvhy S. Cultural differences as a factor influencing environmental preferences students' Dormitory space, Case Study: Iran and Cyprus. Journal Research Association of Iranian Architectural. $2014 ; 3$.

80) Vaughan S, Sanders T, Crossley N, O'neill P, Wass V. Bridging the gap: the roles of social capital and ethnicity in medical student achievement. Med Educ. 2015; 49(1): 114-23. doi: 10.1111/medu.12597. PMID: 25545579.

81) Beehr TA, Glazer S. A cultural perspective of social support in relation to occupational stress. In Exploring theoretical mechanisms and perspectives. Emerald Group Publishing Limited. 2001; 1: 97-142. 